\title{
Imobilização de lipases produzidas por fermentação em estado sólido utilizando Penicillium verrucosum em suportes hidrofóbicos
}

\author{
Immobilization of lipases produced by solid state fermentation from \\ Penicillium verrucosum on hydrophobic supports
}

\author{
Silvana MENONCIN ${ }^{1}$, Natalia Molossi DOMINGUES ${ }^{1}$, Denise Maria Guimarães FREIRE ${ }^{2}$, \\ José Vladimir OLIVEIRA ${ }^{1}$, Marco Di LUCCIO ${ }^{1}$, Helen TREICHEL ${ }^{1 *}$, Débora de OLIVEIRA ${ }^{1}$
}

\section{Resumo}

O principal interesse em imobilizar uma enzima é obter um biocatalisador com atividade e estabilidade que não sejam afetadas durante o processo, em comparação à sua forma livre. Aliado ao potencial biotecnológico que as lipases apresentam, a aplicação destas em nível industrial requer a investigação de técnicas viáveis para reutilização e aumento da estabilidade, conferindo relevância aos processos de imobilização. Neste trabalho investigou-se a imobilização da lipase produzida por fermentação em estado sólido utilizando Penicillium verrucosum em dois suportes hidrofóbicos; Accurel EP 1000 e Carvão Ativo. Para a imobilização das lipases foi adicionado $1 \mathrm{~g}$ de suporte a $50 \mathrm{~mL}$ de uma solução enzimática, estes permaneceram em contato por 2 horas em banho de gelo. Depois de decorrido este tempo, a solução foi filtrada e a enzima imobilizada colocada em dessecador por 48 horas e então feita a medida da atividade lipásica, proteína e cálculo da atividade específica. Através dos resultados obtidos, verificou-se que lipase imobilizada em carvão ativo apresentou valores de atividade específica superiores aos obtidos quando da utilização de Accurel EP 1000 como suporte. Utilizando carvão ativo como suporte, a atividade específica foi de 1533422,5 U/mg de proteína, rendimento de 30,4\% e retenção de 382,5\%.

Palavras-chave: Lipases; Penicillium verrucosum; imobilização.

\begin{abstract}
The major interest in the immobilization of enzymes is obtaining a biocatalyst with activity and stability that are not affected during the process when compared to the free enzyme. The application of lipases in industries requires the study of techniques suitable for reuse and stability increase such as immobilization strategies. This work studied the immobilization of lipases produced by solid state fermentation from Penicillium verrucosum using two hydrophobic supports: Accurel EP 1000 and activated carbon. For the lipase immobilization, $1 \mathrm{~g}$ of support was added to $50 \mathrm{~mL}$ of an enzyme solution and kept for 2 hour in an ice bath. The solution was then filtered and the immobilized enzyme was stored in a dissecator for 48 hour before the assays for lipase activity, protein, and specific lipase activity. The results showed that the lipase immobilized in activated carbon presented higher specific activity than the lipase immobilized in Accurel EP 1000. The use of activated carbon as support led to a specific activity of $1.5 \times 10^{6} \mathrm{U} / \mathrm{mg}$ of protein, yield of $30.42 \%$, and retention of $382.516 \%$.

Keywords: Lipases; Penicillium verrucosum; immobilization.
\end{abstract}

\section{Introdução}

As lipases (triacilglicerol éster hidrolases, EC 3.1.1.3) são enzimas que catalisam a quebra de gorduras e óleos liberando ácidos graxos, diacilgliceróis, monoacilgliceróis e glicerol. As lipases são originárias de um grande número de bactérias, fungos, plantas e animais, tendo suas propriedades variáveis de acordo com sua procedência (SAXENA et al., 2003). As lipases provenientes de microrganismos constituem um grupo de valiosas enzimas de aplicação biotecnológica, devido principalmente à versatilidade de suas propriedades, no que se refere à atuação enzimática, especificidade pelo substrato e facilidade de produção em grandes quantidades (HASAN; SHAH; HAMEED, 2006, VILLENEUVE et al., 2000, PALEKAR; VASUDIVAN; YAN, 2000).
As enzimas podem ser aplicadas em inúmeras áreas, tais como: na indústria oleoquímica em processos como hidrólise, glicerólise e alcoólise; na indústria têxtil (melhoria da qualidade e propriedade dos tecidos) (HASAN; SHAH; HAMEED, 2006); na indústria de detergentes (remoção de manchas de batom, frituras, manteiga, azeites, molhos, etc.) (CASTRO et al., 2004); na indústria de alimentos, na produção de ácidos graxos poliinsaturados (aditivos de alimentos) e na modificação de sabores (processo de fermentação de salame e vinho) (HASAN; SHAH; HAMEED, 2006), entre outras. No entanto, sua utilização é reduzida devido aos altos custos de produção, sendo sugerida como um fator de redução destes custos a utilização da fermentação em estado sólido como método de produção.

Recebido para publicação em 5/12/2007

Aceito para publicação em 28/10/2008 (003069)

Departamento de Engenharia de Alimentos, Universidade Regional Integrada - URI, Campus de Erechim, Av. Sete de Setembro, 1621, Erechim, RS, CEP 99700-000,

E-mail: helentreichel@pq.cnpq.br

Instituto de Química, Centro de Tecnologia, Universidade Federal do Rio de Janeiro - UFRJ, Rio de Janeiro, CEP 21945-970, RJ, Brazil

${ }^{*}$ A quem a correspondência deve ser enviada 
Uma das principais características da Fermentação em Estado Sólido (FES) é a utilização de substratos com baixa atividade de água, na qual as condições de crescimento aproximam-se do habitat natural de fungos, o que facilita o crescimento deste no substrato sólido e a produção de grandes quantidades de enzimas. Os resíduos gerados nos processos agroindustriais podem ser usados como substrato para o crescimento celular. A matéria orgânica presente neste material é usada como fonte de energia para o crescimento e o carbono para a síntese de biomassa celular e dos produtos do metabolismo microbiano (SILVA et al., 2005).

As enzimas estão sujeitas à inativação por fatores químicos, físicos ou biológicos, que podem ocorrer quando estocadas ou durante o uso. Para que a catálise seja eficiente em um determinado processo, há necessidade de proteger as enzimas da interação com o solvente, meio no qual é realizada a reação e que poderia provocar a inativação, impossibilitando a catálise da reação. Frente a este problema, a técnica da imobilização é utilizada para fornecer estabilidade às enzimas e facilitar sua recuperação e reutilização (VILLENEUVE et al., 2000, DALLA-VECCHIA; NASCIMENTO; SOLDI, 2004).

O método de imobilização por adsorção ainda é o mais comum. Este apresenta baixo custo, poucos efeitos deletérios para atividade e seletividade da enzima (VILLENEUVE et al., 2000). As imobilizações por adsorção são usualmente realizadas pela incubação do suporte e da enzima em tampão ou pela precipitação da lipase com solventes, como acetona, sobre a superfície do suporte. Ao contrário do que ocorre com outras proteínas, a adsorção de lipases é favorecida em meios com baixa força iônica (BASTIDA et al., 1998). As resinas poliméricas como Accurel EP 100 (atualmente Accurel MP 1000), constituídas por polipropileno, e materiais contendo grupos hidrófobos de ligações como octil-agarose são exemplos de suportes que vêm se destacando como sendo apropriados à imobilização das lipases (VILLENEUVE et al., 2000).

Com base nestes aspectos, o objetivo deste trabalho foi estudar a imobilização de lipases produzidas por fermentação em estado sólido utilizando Penicillium verrucosum em diferentes suportes hidrofóbicos.

\section{Material e métodos}

\subsection{Microrganismo e preparo do inóculo}

O fungo Penicillium verrucosum usado para o estudo foi isolado previamente por Freire (1996) em solo brasileiro.

O meio Potato Dextrose Agar (PDA) foi utilizado para o preparo do inóculo, o qual era constituído por PDA 3,9\% (m/v) e água destilada. Após a solubilização completa do componente, $100 \mathrm{~mL}$ de meio foram transferidos para um Erlenmeyer de $500 \mathrm{~mL}$ e autoclavados a $121^{\circ} \mathrm{C}$ por 30 minutos.

Do tubo estoque retirou-se uma alçada, a qual foi transferida para um tubo de ensaio contendo $10 \mathrm{~mL}$ de solução de Tween $80(0,1 \% \mathrm{v} / \mathrm{v})$. Após a homogeneização, retirou-se deste $0,30 \mathrm{~mL}$ contendo uma concentração de esporos de $4 \times 10^{8}$ esporos/g que foi inoculado em Erlenmeyers de $250 \mathrm{~mL}$ contendo o meio PDA já resfriado, incubando-se, a seguir, em câmara de germinação a $27,5^{\circ} \mathrm{C}$ por 7 dias (VARGAS et al., 2008). O recolhimento de esporos foi realizado adicionando-se $10 \mathrm{~mL}$ de solução Tween $80(0,1 \% \mathrm{v} / \mathrm{v})$ e pérolas de vidro estéreis ao Erlenmeyer. Retirouse $1 \mathrm{~mL}$ da solução contendo esporos e realizaram-se diluições sucessivas até $10^{-3} \mathrm{em}$ tubos de ensaio estéreis contendo solução de Tween $80(0,1 \% \mathrm{v} / \mathrm{v})$, sendo as diluições estocadas a $4{ }^{\circ} \mathrm{C}$ por no máximo 15 dias.

\subsection{Produção e concentração de lipases}

O farelo de soja foi utilizado como substrato nos experimentos de fermentação em estado sólido. O farelo de soja foi adquirido do moinho Olfar (Erechim-RS), peneirado (Tyler 35-60) e armazenado em freezer $\left(-14^{\circ} \mathrm{C}\right)$ até o momento da sua utilização. Os experimentos de fermentação em estado sólido foram realizados em béqueres de polipropileno de $500 \mathrm{~mL}$ tampados com manta acrílica.

Em cada béquer foram adicionados $10 \mathrm{~g}$ de farelo de soja e 9,6 mL de água destilada por gotejamento manual com auxílio de pipeta graduada de forma que toda a área do farelo fosse recoberta, obtendo-se um percentual de umidade de $50 \%$. Os béqueres foram autoclavados a $121^{\circ} \mathrm{C}$ por 15 minutos e, após resfriamento, inocularam-se os meios com a suspensão de esporos previamente diluída até a concentração de esporos desejada $\left(4 \times 10^{8}\right.$ esporos/g).

A produção de lipases foi realizada segundo condições otimizadas de temperatura $\left(27,5^{\circ} \mathrm{C}\right)$ e umidade inicial do substrato (55\%) (KEMPKA et al., 2008).

\subsection{Extração das lipases do farelo fermentado $e$ concentração}

Após a produção das enzimas, o farelo de soja fermentado foi submetido ao procedimento de extração das lipases. À $10 \mathrm{~g}$ de farelo fermentado foram adicionados $45 \mathrm{~mL}$ de tampão fosfato de sódio $100 \mathrm{mM} \mathrm{pH} \mathrm{7,0} \mathrm{em} \mathrm{Erlenmeyers} \mathrm{de} 250 \mathrm{~mL}$, seguido de incubação a $37^{\circ} \mathrm{C}$ em agitador orbital a $150 \mathrm{rpm}$ durante 30 minutos. A extração da fração líquida foi realizada por prensagem manual em filtro (KEMPKA et al., 2008).

A concentração do extrato bruto enzimático foi realizada com sulfato de amônio com $60 \%$ de saturação por um tempo de 5 horas, condições otimizadas por Menoncin et al. (2008).

\subsection{Imobilização das lipases}

O extrato concentrado foi imobilizado utilizando o princípio de adsorção. Dois suportes foram utilizados, resina polimérica (Accurel EP 100) e carvão ativo $\mathrm{ANF}^{\circledast}$ (Carvorite - Irati/PR).

Para a imobilização da enzima, 1 g de suporte Accurel EP 100 foi embebido em $10 \mathrm{~mL}$ de etanol, sendo esta solução mantida por 30 minutos em contato sob agitação. Posteriormente, o etanol foi removido e o suporte lavado sucessivas vezes com água destilada. O objetivo deste procedimento foi o deslocamento do ar existente no interior do suporte para permitir o acesso de soluções que contêm a enzima. Na imobilização com carvão ativo esta etapa não foi realizada. 
Aos suportes previamente preparados adicionaram-se $50 \mathrm{~mL}$ de uma solução enzimática contendo $3 \mathrm{~g}$ do extrato bruto concentrado na etapa anterior em $60 \mathrm{~mL}$ de tampão fosfato de sódio $0,05 \mathrm{M}$, a qual foi mantida sob agitação magnética em temperatura de $5{ }^{\circ} \mathrm{C}$ (banho de gelo) por 2 horas. Esta metodologia foi definida após ensaios preliminares nos quais se verificou que, para a imobilização do extrato enzimático, era necessária uma atividade específica mínima para garantir a eficiência da adsorção.

Em tempos de 0, 1, 5, 10, 15, 20, 30, 60, 90, 120 minutos foram retiradas alíquotas de $250 \mu \mathrm{L}$ para determinação da concentração de proteínas e construção de um gráfico do teor de proteína em função do tempo de reação e cálculo do rendimento da imobilização, de acordo com a Equação 1 (KAEWTHONG et al., 2005). A determinação de proteínas foi realizada pelo método de Bradford (BRADFORD, 1976).

Foram medidas também as atividades de hidrólise da solução de entrada e da solução de saída e realizado o cálculo da retenção durante a imobilização através das Equações 2 e 3 (KAEWTHONG et al., 2005).

$\eta(\%)=\frac{P s}{P o} \times 100$

em que: $\eta=$ Rendimento (\%); Ps = quantidade de proteína absorvida; $\mathrm{Po}=$ quantidade de proteína utilizada na imobilização (solução de entrada).

$R a(\%)=\frac{A s \times 100}{A r}$

em que: $\mathrm{Ra}=$ retenção (\%); As = atividade real (atividade da enzima imobilizada) (U); Ar = atividade teórica (U).

$A r=A e-A s$

em que: Ae = atividade lipásica da solução de entrada (U); As = atividade lipásica da solução de saída (U).

Após o término do processo de adsorção, as amostras foram filtradas a vácuo e permaneceram por 48 horas em dessecador. Em seguida, foram medidos a atividade de hidrólise das enzimas imobilizadas e seu conteúdo de água por aparelho Karl Fisher. Foi medida também a proteína da solução de entrada e de saída e da enzima imobilizada pelo método de Bradford, sendo que foram acrescentadas 0,1\% de amostra para a enzima imobilizada com carvão ativo e $2 \%$ para a imobilizada em resina polimérica (Accurel EP 100) em relação ao total de reagente utilizado para a análise. Estas concentrações foram definidas em termos das atividades específicas das enzimas imobilizadas.

\subsection{Determinação da atividade enzimática}

A metodologia utilizada para medida da atividade de hidrólise da enzima imobilizada baseou-se na formação de um produto cromóforo ( $\rho$-nitro fenol) a partir da reação de hidrólise do $\rho$-nitrofenil butirato catalisado por lipases. A utilização deste método deveu-se ao fato da necessidade de um método com maior sensibilidade de detecção da atividade hidrolítica das amostras (BASTIDA et al., 1998).
Para a determinação da atividade de hidrólise por este método, primeiramente foi construída uma curva de calibração utilizando como substrato o $\rho$-nitrofenol-butirato.

Em tubos de ensaio foram adicionados 1,9 mL de tampão fosfato de sódio $25 \mathrm{mM}, 16 \mu \mathrm{L}$ de $\rho$-nitrofenol-butirato e $16 \mu \mathrm{L}$ de extrato enzimático. Os tubos foram incubados em banho agitado a $37^{\circ} \mathrm{C}$ e $150 \mathrm{rpm}$ durante $0,1,2,3,5,7$ e 10 minutos. Decorrido o tempo de reação, as amostras foram colocadas na cubeta e foi feita a leitura em espectrofotômetro a $348 \mathrm{~nm}$. Para as enzimas imobilizadas foi acrescentado $1 \% \mathrm{~m} / \mathrm{v}$ de extrato enzimático, de acordo com testes preliminares. A atividade de hidrólise foi calculada segundo a Equação 4.

$A=\frac{(F \cdot V F \cdot 1000)}{(C C . V A)}$

em que: $\mathrm{A}=$ Atividade de hidrólise $(\mathrm{U}) ; \mathrm{F}=$ Fator da curva obtido do gráfico ABS com tempo; VF = Volume total (amostra + tampão + substrato) $(2 \mathrm{~mL}) ; \mathrm{CC}=$ Coeficiente da curva de Calibração; VA = Volume da Alíquota (substrato).

A partir dos valores de atividade de hidrólise e proteína das amostras foi calculada a atividade específica do extrato enzimático imobilizado, conforme Equação 5.

$A e=\frac{A}{P}$

em que: Ae = Atividade específica (U/mg de proteína); $\mathrm{A}=$ Atividade de hidrólise $(\mathrm{U}) ; \mathrm{P}=$ Proteína (mg de proteína).

\section{Resultados e discussão}

\subsection{Imobilização do extrato enzimático concentrado}

Os resultados obtidos na imobilização da lipase produzida por FES utilizando Penicillium verrucosum como microrganismo estão apresentados na Tabela 1.

Pode-se observar que a enzima imobilizada com carvão ativo apresentou melhores resultados em termos de atividade específica (1533425,5 U/mg de proteína), retenção $(382,5 \%)$ e rendimento (30,42\%). Estes resultados são muito promissores, pois o carvão ativo tem um baixo custo e existem poucos relatos na literatura quanto ao uso deste suporte na imobilização de lipases (KAEWTHONG et al., 2005).

Tabela 1. Valores de atividade específica, retenção, rendimento e conteúdo de água na imobilização da lipase produzida por FES utilizando Penicillium verrucosum.

\begin{tabular}{lcc}
\hline & Accurel EP 100 & Carvão Ativo \\
\hline $\begin{array}{l}\text { Atividade Específica de Entrada } \\
\text { (U/mg de proteína) }\end{array}$ & $10,4 \times 10^{3}$ & $10,4 \times 10^{3}$ \\
$\begin{array}{l}\text { Atividade Específica de Saída } \\
\text { (U/mg de proteína) }\end{array}$ & $7,9 \times 10^{3}$ & $6 \times 10^{3}$ \\
Atividade Específica Imobilizada & $92,4 \times 10^{3}$ & $1,5 \times 10^{6}$ \\
(U/mg de proteína) & & \\
Retenção (Ra) (\%) & 368,1 & 382,5 \\
Rendimento (ๆ) (\%) & 11,7 & 30,4 \\
Conteúdo de água (\%) & 5,5 & 10,0 \\
\hline
\end{tabular}


Observa-se que a retenção obtida em ambos os suportes utilizados foi maior que $100 \%$, significando que além de imobilizar, devido à afinidade da enzima pelo suporte, pode ter ocorrido uma concentração e/ou ativação da enzima na forma imobilizada, obtendo-se, portanto, porcentagens de retenção na ordem de $300 \%$.

Com base nestes resultados, pode-se observar que foram maiores que alguns reportados na literatura. Kaewthong et al. (2005), imobilizando a lipase PS (Amano) em diferentes suportes, obteve rendimentos de 37,16\% para resina polimérica (Accurel EP100, $<200 \mu \mathrm{m}$ ). Quando esta mesma lipase foi imobilizada em Accurel EP $100(200-400 \mu \mathrm{m})$ o rendimento encontrado foi de $31,10 \%, 0,79 \%$ em carbonato de cálcio, 3,56\% em celite, $6,42 \%$ em sílica gel e $0,36 \%$ em carvão ativado. Bryjak e Trochimczuk (2006), na imobilização de lipase de Candida rugosa por adsorção em suportes acrílicos, encontraram rendimento máximo de $25,4 \%$, também menores que os encontrados no presente estudo.

Em termos de retenção de atividade, Knezevic et al. (2002), imobilizando lipases de Candida rugosa em diferentes concentrações de alginato, obtiveram retenção máxima de 79,99\%, sendo esta muito inferior à encontrada neste estudo.

Resultados recentes apresentados na literatura (BAYRAMOGLU; ARICA, 2008, LEE; JO; LEE, 2008, XIAO-JUN; YU; XU, 2008, YONG et al., 2008) têm demonstrado a utilização de nano e micropartículas como suporte para imobilização de lipases. Apesar dos dados satisfatórios obtidos, cabe mencionar o alto custo envolvido na obtenção destes suportes.

Com base nestes aspectos, o estudo de imobilização das lipases produzidas por Penicillium verrucosum em FES apresentado neste trabalho, mostrou-se bastante relevante do ponto de vista do baixo custo de um dos suportes utilizados (carvão ativo), bem como em função dos altos valores de retenção da enzima a este suporte.

\section{Conclusões}

Na imobilização do extrato enzimático concentrado de Penicillium verrucosum obtido por FES, os melhores resultados foram encontrados quando este foi imobilizado em carvão ativo, sendo que, neste caso, a atividade específica foi de $1533422,5 \mathrm{U} / \mathrm{mg}$ de proteína, rendimento de $30,42 \%$ e retenção de $382,516 \%$.

\section{Agradecimentos}

Os autores agradecem ao $\mathrm{CNPq}$, PROCAD/CAPES e Intecnial $\mathrm{S}$ A pelo apoio financeiro e suporte ao desenvolvimento deste trabalho.

\section{Referências bibliográficas}

BASTIDA, A. et al. A single step purification, immobilization, and hyperactivation of lipases via interfacial adsortions on strongly hydrophobic supports. Biotechnology and Bioengineering, v. 58, n. 5, p. 486-493, 1998.

BAYRAMOGLU, G.; ARICA, M. Y. Preparation of poly(glycidylmethacrylatemethylmethacrylate) magnetic beads: Application in lipase immobilization. Journal of Molecular Catalysis B: Enzymatic, v. 55, n. 1-2, p. 76-83, 2008.
BRADFORD, M. M. A rapid and sensitive method for the quantitation of microgram of protein utilizing the principle of protein-drye binding. Analytical Biochemistry, v. 72, n. 1, p. 248-254, 1976.

BRYJAK, J.; TROCHIMCZUK, A W. Immobilization of penicillin acylase on hydrophobic acrylic carriers. Enzyme and Microbial Technology, v. 39, n. 4, p. 573-578, 2006.

CASTRO, H. F. et al. Modificação de óleos e gorduras por biotransformação. Química Nova, v. 27, n. 1, p. 146-156, 2004.

DALLA-VECCHIA, R.; NASCIMENTO, M. G.; SOLDI, V. Aplicações sintéticas de lipases imobilizadas em polímeros. Química Nova, v. 27, n. 4 , p. 623-630, 2004.

FREIRE, D. M. G. Seleção de Microrganismos lipolíticos e estudo da produção de lipases por Penicillium restrictum. Rio de Janeiro, 1996. 185 p. Tese (Doutorado), Departamento de Bioquímica, IQ/ UFRJ.

HASAN, F.; SHAH, A. A.; HAMEED, A. Industrial applications of microbial lipases. Enzyme and Microbial Technology, v. 39, n. 2, p. 235-251, 2006.

KAEWTHONG, W.; SIRISANSANEEYAKUL, S.; PRASERTSAN, P.; H-KITTIKUN, A. Continuous production of monoacylglycerols by glycerolysis of palm olein with immobilized lipase. Process Biochemistry, v. 40, n. 1, p. 1525-1530, 2005.

KEMPKA, A. P. et al. Response surface method to optimize the production and characterization of lipase from Penicillium verrucosum in solid state fermentation. Bioprocess and Biosystems Engineering, v. 31, n. 1, p. 119-125, 2008.

KNEZEVIC, Z. et al. Alginate-immobilized lipase by electrostatic extrusion for the purpose of palm oil hydrolysis in lecithin/isooctane system. Process Biochemistry, v. 38, n. 3, p. 313-318, 2002.

LEE, G.; JOO, H.; LEE, J. The use of polyaniline nanofibre as a support for lipase mediated reaction. Journal of Molecular Catalysis B: Enzymatic, v. 54, n. 3-4, p. 116-121, 2008.

MENONCIN, S. et al. Study of the extraction, concentration and partial characterization of lipases obtained from Penicillium verrucosum using the solid-state fermentation of soybean bran. Food Technology and Biotechnology, DOI: 10.1007/s11947-008-0104-8, aceito para publicação.

PALEKAR, A. A.; VASUDIVAN, P. T.; YAN, S. Purification of Lipase: a Review. Biocatalysis and Biotransformation, v. 18, n. 3, p. 177-200, 2000

SAXENA, R. K. et al. Purification strategies for microbial lipases. Journal Microbiology Methodology, v. 52, n. 1, p. 1-18, 2003.

SILVA, D. et al. Production of pectinase by solid-state fermentation with Penicillium viridicatum RFC3. Process Biochemistry, v. 40, n. 8, p. 2885-2889, 2005.

VARGAS, G. D. et al. Optimization of lipase production by Penicillium simplicissimum in soybean meal. Journal of Chemical Technology and Biotechnology, v. 83, n. 47-54, p. 47-54, 2008.

VILLENEUVE, P. et al. Customizing lipases for biocatalysis: a survey of chemical, physical and molecular biological approaches. Journal of Molecular Catalysis B: Enzymatic, v. 9, n. 4-6, p. 113-148, 2000.

XIAO-JUN, H.; YU, A.; XU, Z. Covalent immobilization of lipase from Candida rugosa onto poly(acrylonitrile-co-2-hydroxyethyl methacrylate) electrospun fibrous membranes for potential bioreactor application. Bioresource Technology, v. 99, n. 13, p. 5459-5465, 2008.

YONG, Y. et al. Preparation and application of polymer-grafted magnetic nanoparticles for lipase immobilization. Journal of Magnetism and Magnetic Materials, v. 320, n. 19, p. 2350-2355, 2008. 